\title{
Experimental and Numerical Study of the Effects of Solution Concentration and Temperature on Concrete under External Sulfate Attack
}

DOI:

10.1016/j.cemconres.2020.106284

\section{Document Version}

Accepted author manuscript

Link to publication record in Manchester Research Explorer

Citation for published version (APA):

Zou, D., Qin, S., Liu, T., \& Jivkov, A. (2021). Experimental and Numerical Study of the Effects of Solution Concentration and Temperature on Concrete under External Sulfate Attack. Cement and Concrete Research, 139, [106284]. https://doi.org/10.1016/j.cemconres.2020.106284

\section{Published in:}

Cement and Concrete Research

\section{Citing this paper}

Please note that where the full-text provided on Manchester Research Explorer is the Author Accepted Manuscript or Proof version this may differ from the final Published version. If citing, it is advised that you check and use the publisher's definitive version.

\section{General rights}

Copyright and moral rights for the publications made accessible in the Research Explorer are retained by the authors and/or other copyright owners and it is a condition of accessing publications that users recognise and abide by the legal requirements associated with these rights.

\section{Takedown policy}

If you believe that this document breaches copyright please refer to the University of Manchester's Takedown Procedures [http://man.ac.uk/04Y6Bo] or contact uml.scholarlycommunications@manchester.ac.uk providing relevant details, so we can investigate your claim.

\section{OPEN ACCESS}




\title{
Experimental and Numerical Study of the Effects of Solution Concentration and Temperature on Concrete under External Sulfate Attack
}

\author{
Dujian Zou ${ }^{\text {a }}$, Shanshan Qin ${ }^{\text {a }}$, Tiejun Liu ${ }^{\mathrm{a},{ }^{*}}$, Andrey Jivkov ${ }^{\mathrm{b}}$ \\ ${ }^{a}$ School of Civil and Environmental Engineering, Harbin Institute of Technology, Shenzhen, Shenzhen 518055, P.R. \\ China \\ ${ }^{\mathrm{b}}$ School of Mechanical, Aerospace and Civil Engineering, The University of Manchester, Manchester M13 9PL, \\ United Kingdom
}

\begin{abstract}
The work reports on an experimental programme, conducted to validate comprehensively our previously proposed coupled chemo-transport model for external sulfate attack on concrete. Specifically, the effects of the concentration of sulfate solution and temperature on the distribution of sulfate ions in concrete are experimentally investigated and used to demonstrate the accuracy of the modelling framework. Further, the profile of aluminate depletion and the leaching depth numerically are investigated. For all cases the model predictions are in good agreement with the experimental results, showing increases of the concentration of sulfate ions in concrete with higher concentrations of sulfate solution and higher temperatures. It is concluded that higher sulfate solution concentration and temperature enhance the processes involved in the external sulfate attack on concrete, namely diffusion of sulfate ions and their chemical reactions with concrete. It is found that these parameters affect the external sulfate attack predominantly via the chemical reaction process.
\end{abstract}

Keywords: External Sulfate Attack; Sulfate Solution Concentration; Temperature; Calcium Leaching; Numerical Modeling

Corresponding author. Tel.: 86-755-26033368; Fax: 86-755-26033509

E-mail address: liutiejun@hit.edu.cn (T.J Liu) 


\section{INTRODUCTION}

Sulfate attack is a very complex degradation mechanism in concrete, involving physical-chemical processes, such as ion diffusion, chemical reaction, and expansion damage [1,2]. The ingress of external sulfate ions upsets the equilibrium of the concrete pore solution, resulting in the dissolution of portlandite $(\mathrm{CH})$, in the decalcification of calcium silicate hydrates $(\mathrm{C}-\mathrm{S}-\mathrm{H})$ and in the formation of expansive products [3]. The poorly soluble expansive products such as gypsum and ettringite could fill in pores, leading to microcracking and expansion of cement-based materials [4,5]. Moreover, the decalcification of C-S-H reduces the strength of concrete since the bond between cement paste and aggregate weakens [68]. These coupled effects may cause failures of concrete structures in sulfate-aggressive environments, which cannot be predicted on the base of standard structural analysis and design methods.

In our recent work [9], a coupled chemo-transport model for the external sulfate attack on concrete was established by considering the influences of calcium leaching and temperature. Calcium leaching accompanied by sulfate attack starts with dissolution of portlandite $(\mathrm{CH})$ and proceeds with decalcification of calcium silicate hydrates $(\mathrm{C}-\mathrm{S}-\mathrm{H})$ [10,11]. The dissolved calcium ions in concrete continue reacting with the attacking sulfate ions. Meanwhile, the free volume created due to the dissolution of $\mathrm{CH}$ and $\mathrm{C}-\mathrm{S}-\mathrm{H}$ increases diffusivity $[12,13]$. Our model assumed that calcium leaching was a combination of diffusion and dissolution processes and utilized a solid-liquid equilibrium curve to describe it. The accelerating effects of immersion in sulfate solution and porosity changes during calcium leaching were also accounted for. The impact of temperature variation was reflected in the generation of temperature gradient, the rate constants of chemical reactions and calcium leaching, and the diffusion coefficients of ions. A brief description of this model is given in Section 2 in order to relate it to the experimental and simulation programmes of the current work.

The aim of the present work is to validate experimentally our recently proposed model and demonstrate its predictive capabilities in terms of leaching depth and aluminate depletion. The validation requires experimental data and simulation results showing the effects of the concentration of sulfate solution and temperature on concrete. To this end, three different concentrations of sulfate solution, namely 3, 5, and 7 wt. \%, and three different temperatures of 290, 298, and 308 K were considered. The variation of sulfate content with depth was measured by the barium sulfate gravimetric method and compared with corresponding simulations with the model. In addition, the profile of aluminate depletion and the leaching 
depth were numerically calculated to evaluate the impacts of sulfate solution concentration and temperature on the chemical reactions and diffusion of ions, respectively. Good agreement between model predictions and experimental data is demonstrated that higher sulfate solution concentration and temperature enhance the diffusion and chemical reaction processes involved in the external sulfate attack on concrete.

\section{CHEMO-TRANSPORT MODEL BRIEF}

The coupled chemo-transport model for the external sulfate attack on concrete proposed in our previous work [9] accounts for the effects of calcium leaching and temperature on concrete deterioration assuming the following:

- Concrete is an isotropic porous material in the saturated state.

- The transport process is driven by a concentration gradient and obeys Fick's second law of diffusion.

- A second-order chemical reaction between penetrating sulfate ions and hydration products is considered.

- Volume increased by ettringite formation is assumed to cause the expansion.

In a cement-based material, penetrating sulfate ions react with the dissolved calcium ions from the portlandite $(\mathrm{CH})$ or calcium silicate hydrates $(\mathrm{C}-\mathrm{S}-\mathrm{H})$ to form gypsum $\left(\mathrm{C} \bar{S} H_{2}\right)$ as follows:

$$
\mathrm{Ca}^{2+}+\mathrm{SO}_{4}^{2-}+2 \mathrm{H} \rightarrow \overline{\mathrm{CS}} \mathrm{H}_{2}
$$

Three main compounds, namely tricalcium aluminate $\mathrm{C}_{3} \mathrm{~A}$, tetracalcium aluminate $\mathrm{C}_{4} \mathrm{AH}_{13}$, and monosulfate $\mathrm{C}_{4} \mathrm{~A} \overline{\mathrm{S}} \mathrm{H}_{12}$, are considered to react with gypsum leading to the formation of ettringite $\left(\mathrm{C}_{6} \mathrm{AS}_{3} \mathrm{H}_{32}\right)$ :

$$
\begin{gathered}
\mathrm{C}_{3} \mathrm{~A}+3 \overline{\mathrm{CS}} \mathrm{H}_{2}+26 \mathrm{H} \rightarrow \mathrm{C}_{6} \mathrm{AS}_{3} \mathrm{H}_{32} \\
\mathrm{C}_{4} \mathrm{AH}_{13}+3 \bar{C}_{\bar{S}} \mathrm{H}_{2}+14 \mathrm{H} \rightarrow \mathrm{C}_{6} \mathrm{AS}_{3} \mathrm{H}_{32}+\mathrm{CH} \\
\mathrm{C}_{4} \mathrm{~A} \overline{\mathrm{S}} \mathrm{H}_{12}+2 \mathrm{C} \overline{\mathrm{S}} \mathrm{H}_{2}+16 \mathrm{H} \rightarrow \mathrm{C}_{6} \mathrm{AS}_{3} \mathrm{H}_{32}
\end{gathered}
$$

Following previous works [2,14,15], Eqs. (2)-(4) are integrated in a single expression as follows:

$$
\mathrm{CA}+q \overline{\mathrm{CS}}_{2} \rightarrow \mathrm{C}_{6} \mathrm{AS}_{3} \mathrm{H}_{32}
$$

where $\mathrm{CA}$ is an equivalent grouping of the reacted calcium aluminates $\left(P_{\mathrm{i}}\right)$ defined by $\mathrm{CA}=\sum_{i=1}^{3} \lambda_{i} \cdot P_{i}$, and $q$ represents the stoichiometric weighted coefficient of the sulfate phase expressed in $q=3 \lambda_{1}+3 \lambda_{2}+2 \lambda_{3} ; \quad \lambda_{i}=P_{i}\left(\sum_{i=1}^{3} P_{i}\right)^{-1}$ is the fraction of the reacted aluminate phase. 
By assuming Fick's second law of diffusion and second-order chemical reaction kinetics, the system of governing equations for sulfate ions, gypsum, and calcium aluminates can be obtained according to Eqs. (1) and (5) as follows:

$$
\begin{gathered}
\frac{\partial c_{S O_{4}^{2-}}}{\partial t}=\operatorname{div}\left[D_{S O_{4}^{2-}}\left(\nabla c_{S O_{4}^{2-}}+c_{S O_{4}^{2-}} \nabla \operatorname{In} \gamma_{S O_{4}^{2-}}+\frac{c_{S O_{4}^{2-}} \operatorname{In} \gamma_{S O_{4}^{2-}} c_{S O_{4}^{2-}}}{T} \nabla T\right)\right]-k_{1} c_{S O_{4}^{22}} c_{C a^{2+}} \\
\frac{\partial c_{g p y}}{\partial t}=k_{1} c_{S O_{-}^{22}} c_{C a^{2+}}-k_{2} c_{g p y} c_{C A} \\
\frac{\partial c_{C A}}{\partial t}=-k_{2} \frac{c_{g p y} c_{C A}}{q}
\end{gathered}
$$

where $c_{S O 4^{2}}, c_{C a^{2+}}, c_{g p y}$, and $c_{C A}$, measured in $\mathrm{mol} / \mathrm{m}^{3}$, represent the concentration of sulfate ions, calcium ions, secondary gypsum, and equivalent lumped calcium aluminates in matrix, respectively; $t$ (s) denotes the diffusion time; $k_{1}$ and $k_{2}$ $\left(\mathrm{m}^{3} / \mathrm{mol} / \mathrm{s}\right)$ are the chemical reaction rate constants of Eqs. (1) and (5), respectively; $D_{i}\left(\mathrm{~m}^{2} / \mathrm{s}\right)$ is the effective diffusion coefficient of ions in the matrix; $\gamma_{i}$ stands for the chemical activity coefficient calculated by the modified Davies equation [16]; $i$ represents sulfate ions in Eq. (6) and calcium ions in Eq. (11); $T(\mathrm{~K})$ is the temperature. It should be noted that the amount of calcium aluminate consumed is equal to the amount of ettringite formed.

Since calcium ions are consumed by sulfate ions, they are continuously replenished with the leaching process, i.e. the dissolution of portlandite $(\mathrm{CH})$ and the decalcification of calcium silicate hydrates $(\mathrm{C}-\mathrm{S}-\mathrm{H})$. The calcium leaching process is described by a typical solid-liquid equilibrium curve which is obtained from experimental results [17-19]. The equilibrium of the calcium ions between the solid phases $(\mathrm{C}-\mathrm{S}-\mathrm{H}$ and $\mathrm{CH})$ and the pore solution is expressed by:

$$
c_{c a}^{s}(x, t)= \begin{cases}\left\{\frac{-2}{x_{1}^{3}} c_{C a^{2+}}^{3}(x, t)+\frac{3}{x_{1}^{2}} c_{C a^{2+}}^{2}(x, t)\right]\left\{C_{C S H 0}\left[\frac{c_{C a^{2+}}(x, t)}{C_{\text {satu }}}\right]^{1 / 3}\right\} & 0 \leq c_{\mathrm{Ca}^{2+}}(x, t) \leq x_{1} \\ \left\{C_{\mathrm{CSH} 0}\left[\frac{c_{C a^{2+}}(x, t)}{C_{\text {satu }}}\right]^{1 / 3}\right\} & x_{1}<c_{\mathrm{Ca}^{2+}}(x, t) \leq x_{2} \\ \left\{C_{\mathrm{CSH} 0}\left[\frac{c_{\mathrm{Ca}^{2+}}(x, t)}{C_{\text {satu }}}\right]^{1 / 3}\right\}+\frac{C_{C H 0}}{\left(C_{\text {satu }}-x_{2}\right)^{3}}\left[c_{\mathrm{Ca}^{2+}}(x, t)-x_{2}\right]^{3} & x_{2}<c_{\mathrm{Ca}^{2+}}(x, t) \leq C_{\text {satu }}\end{cases}
$$

where $c_{c a}^{s}(x, t)$ and $c_{C a^{2+}}(x, t)\left(\mathrm{mol} / \mathrm{m}^{3}\right)$ represent the concentrations of calcium ions in the solid phases and in the pore solution; $C_{C S H 0}$ and $C_{C H 0}\left(\mathrm{~mol} / \mathrm{m}^{3}\right)$ are the initial concentrations of calcium ions in the solid phase of the C-S-H gel and calcium hydroxide $(\mathrm{CH})$, and $C_{\text {satu }}\left(\mathrm{mol} / \mathrm{m}^{3}\right)$ stands for the concentration of calcium ions in the saturated liquid phase; $x_{1}$ $\left(\mathrm{mol} / \mathrm{m}^{3}\right)$ indicates the concentration of calcium ions in the liquid phase when the C-S-H gel begins to rapidly transform into silica gel, and $x_{2}\left(\mathrm{~mol} / \mathrm{m}^{3}\right)$ is the concentration of calcium ions in the liquid phase when the dissolution of C-S-H gel 
starts since the calcium hydroxide is completely dissolved. The leaching process can be divided into three stages. Due to the highest solubility of $\mathrm{CH}$, the dissolution of $\mathrm{CH}$ occurs first, when $c_{C a}{ }^{2+}(x, t)$ decreases from $C_{\text {satu }}$. After the $\mathrm{CH}$ is fully dissolved, i.e. when $c_{C a}{ }^{2+}(x, t)$ drops below $x_{2}$, the dissolution of C-S-H starts. When $c_{C a}^{2+}(x, t)$ falls below $x_{1}$, the C-S-H gel decomposes rapidly into silica gel. Wan et al. [20] experimentally found that the values of $C_{\text {satu }}, x_{1}$, and $x_{2}$ increase by up to two orders of magnitude in $6 \mathrm{~mol} / \mathrm{L}$ nitrate solution. Based on the research of Phung et al. [12], these values are assumed to have a linear relationship with the concentration of sulfate solution in this work, as defined by:

$$
\left\{\begin{array}{l}
x_{1}=2+\frac{c_{s 0}}{S_{0}}(273-2) \\
x_{2}=20+\frac{c_{s 0}}{S_{0}}(2320-20) \\
C_{\text {satu }}=22+\frac{c_{s 0}}{S_{0}}(2730-22)
\end{array}\right.
$$

where $S_{0}$ is the concentration of ammonium nitrate solution, i.e. $6 \mathrm{~mol} / \mathrm{L}$, and $c_{s 0}$ stands for the concentration of sulfate solution. Then, by taking account of the diffusion and dissolution processes, the governing equation for calcium ions is given by:

$$
\frac{\partial c_{C a^{2+}}}{\partial t}=\operatorname{div}\left[D_{\mathrm{Ca}^{2+}}\left(\nabla c_{\mathrm{Ca}^{2+}}+c_{\mathrm{Ca}^{2+}} \nabla \operatorname{In} \gamma_{\mathrm{Ca}^{2+}}+\frac{c_{\mathrm{Ca}^{2+}} \operatorname{In} \gamma_{\mathrm{Ca}^{2+}} c_{\mathrm{Ca}^{2+}}}{T} \nabla T\right)\right]-\frac{\partial c_{c a}^{s}}{\partial t}
$$

In Eqs. (6) and (11), the influence of temperature variation is reflected in the generation of temperature gradient, in the rate constants of chemical reactions and calcium leaching, and in the diffusion coefficients of ions. Moreover, the influence of changes in volume, resulting from the chemical reactions and the accompanied calcium leaching process, on the effective diffusion coefficients of ions is accounted for. On the one hand, the diffusion coefficients of ions decrease with porosity reduction due to pores filling by reaction products. On the other hand, when the strain created by volume expansion reaches the tensile strength of concrete, the formation of microcracks improves the bulk diffusivity. The current work investigates these two aspects, and further details can be found in our previous paper [9]. 


\section{EXPERIMENTAL PROCEDURES}

\subsection{Materials}

The chemical composition of the ordinary Portland cement 42.5 $\mathrm{N}$ type used in the experiments is given in Table 1, with 5.92 wt.\% $\mathrm{C}_{3} \mathrm{~A}$ in the cement. Medium sand was used as fine aggregate, coarse aggregates were crushed stones with maximal diameter of $15 \mathrm{~mm}$. Concrete mix proportions by weight, binder/water/sand/gravel, were 1:0.48:1.98:2.94. Twenty-one concrete specimens with dimensions $100 \mathrm{~mm} \times 100 \mathrm{~mm} \times 400 \mathrm{~mm}$ and three concrete specimens with dimensions $100 \mathrm{~mm} \times 100 \mathrm{~mm} \times 100 \mathrm{~mm}$ were cast to determine the effect of concentration of sulfate ions and the initial porosity, respectively. The casting and curing methods followed the Standard for Test Method of Mechanical Properties on Ordinary Concrete (GB/T, 50081) [21].

Table 1. Chemical composition of the ordinary Portland cement used.

\begin{tabular}{cccccccc}
\hline Chemical compositions & $\mathrm{SiO}_{2}$ & $\mathrm{Al}_{2} \mathrm{O}_{3}$ & $\mathrm{CaO}$ & $\mathrm{MgO}$ & $\mathrm{SO}_{3}$ & $\mathrm{Fe}_{2} \mathrm{O}_{3}$ & others \\
\hline Mass (\%) & 20.60 & 5.03 & 65.06 & 0.55 & 2.24 & 4.38 & 2.14 \\
\hline
\end{tabular}

\subsection{Experimental design}

\subsubsection{Porosity}

After the specimens were cured in tap water for 28 days, the three concrete cubes saturated with water were weighed and then put in an oven at $378 \mathrm{~K}\left(105^{\circ} \mathrm{C}\right)$. After heating for 30 days, the specimens were weighted every day. The final weight of the dried specimens was determined until the difference between two successive weighing was less than $0.5 \%$. The initial porosity was then calculated as the average value of the porosity of the three specimens obtained by:

$$
\varphi_{0}=\frac{m_{1}-m_{2}}{\rho_{w}}
$$

where $m_{1}$ and $m_{2}$ are the weight of the saturated and dried specimen, and $\rho_{w}$ stands for the density of water, i.e. $1.0 \mathrm{~g} / \mathrm{cm}^{3}$.

\subsubsection{Concentration of sulfate ions}

The specimens with the dimensions $100 \mathrm{~mm} \times 100 \mathrm{~mm} \times 400 \mathrm{~mm}$ were used to calculate the concentration of sulfate ions in concrete. Twenty-one specimens were fully immersed in different sodium sulfate solutions. As shown in Fig. 1, 
four sides of the specimens (with light yellow color) were sealed by brushing a thick layer of liquid wax and waiting for it to solidify; two opposite sides (two $100 \mathrm{~mm} \times 400 \mathrm{~mm}$ surfaces with dark color) were left uncovered for the diffusion of the sulfate solution; thus, the transfer of sulfate ions can be simplified as a one-dimensional diffusion process. The direction of diffusion is marked by the red arrow. The details of the experiments are presented in Table 2. Group 1 was used to validate the developed model, while group 2 and group 3 were employed to respectively analyze the effects of sulfate solution concentration and temperature on the transfer of sulfate ions. Three different concentrations of sulfate solution, namely 3, 5, and 7 wt.\%, and three different temperatures, namely 290, 298, $308 \mathrm{~K}$, were considered in this study. The concrete specimens were placed in a heating humid chamber, the temperature of which was set at 290 and $308 \mathrm{~K}$, and one set of the specimens was put in the laboratory at room temperature $(298 \mathrm{~K})$. In this case, there is no temperature gradient as the specimens were immersed in solutions with a constant temperature. The concentration of sulfate ions in concrete was first measured after the specimens were immersed in the sulfate solution for 60 days, and then it was regularly measured every 30 days.

Table 2. The scheme of external sulfate attack experiments.

\begin{tabular}{|c|c|c|c|c|c|}
\hline Group & $\begin{array}{l}\text { Solution concentration } \\
\text { (wt. \%) }\end{array}$ & $\begin{array}{c}\text { Temperature } \\
(\mathrm{K})\end{array}$ & Number & $\begin{array}{l}\text { Immersion time } \\
\text { (days) }\end{array}$ & $\begin{array}{c}\text { Specimen dimensions } \\
(\mathrm{mm} \times \mathrm{mm} \times \mathrm{mm})\end{array}$ \\
\hline 1 & 5 & 298 & 3 & & \\
\hline 2 & $3,5,7$ & 298 & 9 & $60,90,120,150$ & $100 \times 100 \times 400$ \\
\hline 3 & 5 & $290,298,308$ & 9 & & \\
\hline
\end{tabular}

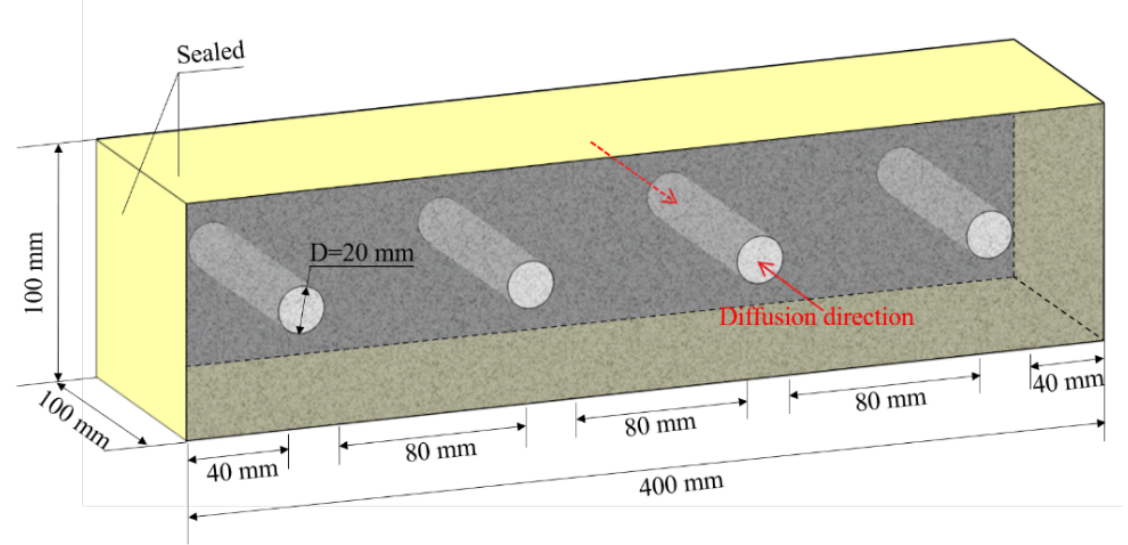

Fig. 1 The drilling diagram of specimens. 


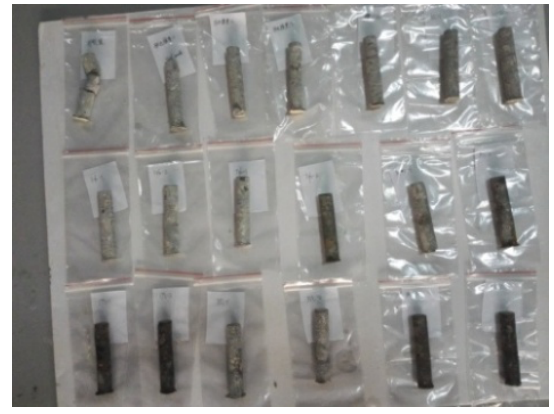

(a) Cylinder samples

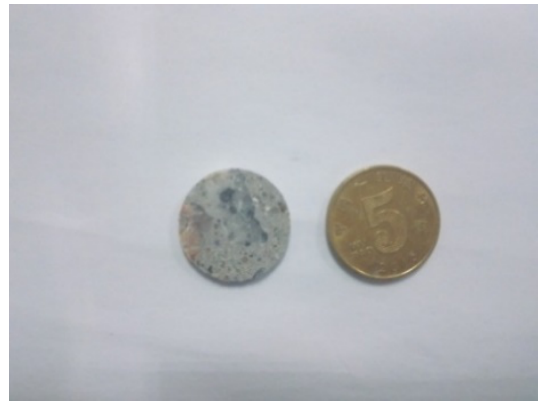

(b) Slices

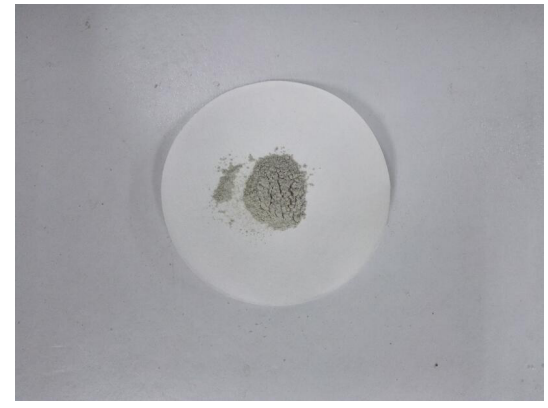

(c) Powder

Fig. 2. The processing of the samples.

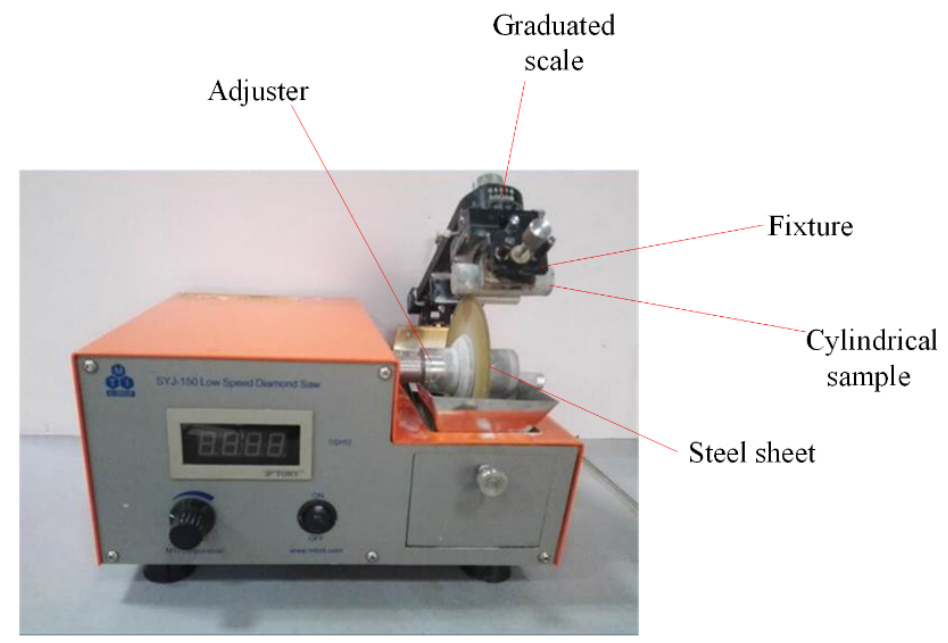

Fig. 3. Diamond cutting machine.

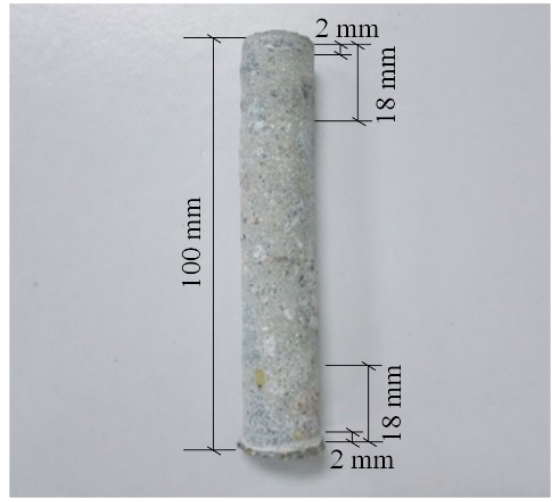

(a) Group 1

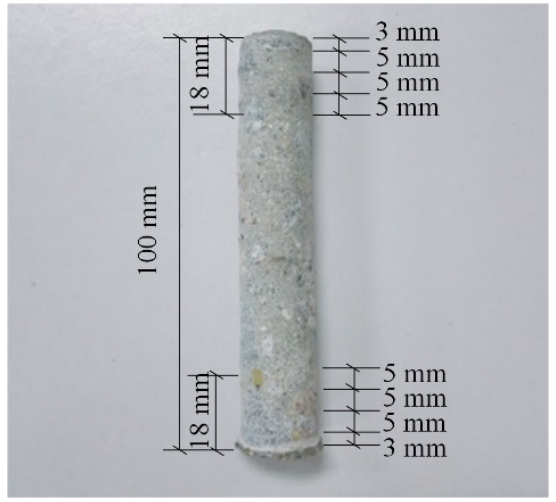

(b) Groups 2 and 3

Fig. 4. A sketch of the cylinder sample cutting. 
The concentrations of sulfate ions at different depths of the specimens were measured using the barium sulfate gravimetric method as described in General Test Method in Salt Industry-Determination of Sulfate (GB/T 13025.8, 2012) [22]. This method is used in our tests considering the equipment in the laboratory and requirements for the operator. At each test time, one cylindrical sample with a diameter of $20 \mathrm{~mm}$ is extracted from the concrete specimens. The drilling diagram is shown in Fig. 1, a total of four measurements was carried out on one specimen with the maximum immersion time of 150 days. The shortest distance between the hole and the outer edge of the specimen is $40 \mathrm{~mm}$, and between two cylinders is $80 \mathrm{~mm}$. It is assumed that the influence of drilling a hole on the transport of the remaining sample is negligible because of the sufficiently large distance and consistent direction of drilling and main diffusion. The processing of the samples is presented in Fig. 2. A diamond cutting machine is used to cut the cylinders to obtain the slices. As shown in Fig. 3, the cylinder is placed on the fixture and the position of the steel sheet is adjusted to determine the thickness of cutting slice by using the adjuster and graduated scale. The precision can reach $0.01 \mathrm{~mm}$. The slices cut from the cylinder samples were dried in an oven at $313 \mathrm{~K}\left(40{ }^{\circ} \mathrm{C}\right)$ for 24 hours, cooled to room temperature and then ground into powder. Group 1 was set as the verification group to observe the discrepancy between the numerical and experimental results. For this purpose, each slice had a thickness of $2 \mathrm{~mm}$ to obtain a larger number of data points (see Fig. 4a). Groups 2 and 3 were used to verify the trend of the numerical results of the model by varying the concentration of the sulfate solution and temperature. To this end, the thickness of the first slice was $3 \mathrm{~mm}$, but the remaining slices were five-millimeter thick (see Fig. 4b). The midpoint of each slice indicates the depth at which the results are obtained. For example, the measured sulfate ion concentration of the first slice in Group 1 represents the result at the depth of $1 \mathrm{~mm}$. Similarly, the concentration of sulfate ions at the depths of $3,5,7 \mathrm{~mm}$, and so on, can be obtained. The maximum calculated depth is $18 \mathrm{~mm}$ since the diffusion depths of sulfate ions are limited in a short term. It should be noted that the obtained concentrations of sulfate ions include the content of sulfate ions in the solution and solid phases.

\section{RESULTS AND DISCUSSION}

\subsection{Concentration of sulfate ions}

Fig. 5 shows the concentrations of sulfate ions of Group 2 at the depth of $1.5 \mathrm{~mm}$ under various sulfate solution concentrations. At a higher solution concentration, more sulfate ions penetrate into the concrete for the same immersion 
time. However, the concentration of sulfate ions at the depth of $1.5 \mathrm{~mm}$ is not necessarily a monotonically increasing function of time. For example, the concentration of sulfate ions after 90 days of immersion are slightly lower than those after 60 days at solution concentrations of 3\% and 5\%. After 90 days, the concentration of sulfate ions monotonically increases. This may be associated with the formation of expansive products under sulfate attack. At the early stage, the expansive products filling the pores impede the transport of sulfate ions. The accumulation of expansive products causes microcracking when the stresses induced by the increased volume of expansive products are larger than the tensile strength of materials. This leads to accelerated diffusion of sulfate ions. Compared with the solution concentrations of $3 \%$ and $5 \%$, the blocking effect of expansive products on the diffusion of sulfate ions at the solution concentration of $7 \%$ seems to be limited. This may be attributed to the greater concentration gradient promoting the diffusion of sulfate ions. Moreover, more expansive products are generated in a shorter time speeding up the appearance of microcracks [23]. These results indicate that highly concentrated solutions would accelerate the sulfate attack on concrete.

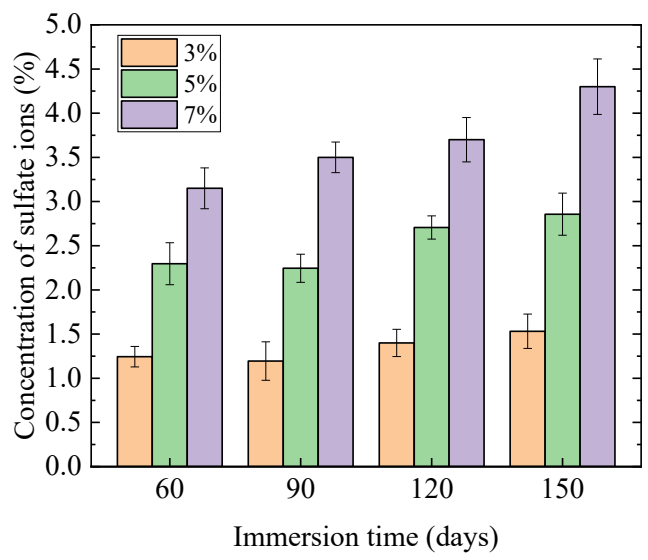

Fig. 5. Concentration of sulfate ion under various sulfate solution concentrations

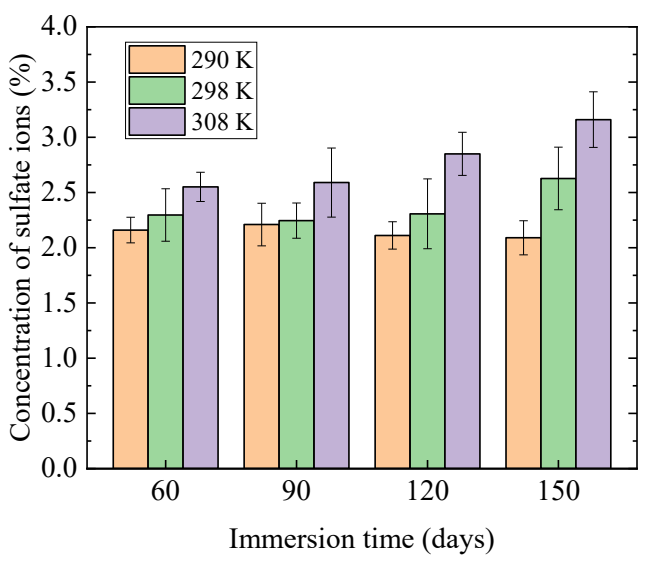

Fig. 6. Concentration of sulfate ion at different temperatures

The concentration of sulfate ions at the depth of $1.5 \mathrm{~mm}$ at different temperatures (Group 3) are presented in Fig. 6. The higher temperature, the larger concentration of sulfate ions is obtained. When the temperature rises from $298 \mathrm{~K}$ to 308 $\mathrm{K}$, the concentration of sulfate ions is increased by $20.3 \%$ at 150 days, which is much lower than the $50.5 \%$ increase when the solution concentration increases from $5 \%$ to $7 \%$. This shows that concrete under sulfate attack is more susceptible to the sulfate solution concentration than to temperature variations. After 90 days of immersion, the concentration of sulfate ions decreases slightly with increase of the immersion time at temperatures of $290 \mathrm{~K}$. Since both the diffusion coefficient of sulfate ions and the chemical reaction rate constants are lower at lower temperatures, the expansive products formed in 
the early stage could have stronger blocking effect on the diffusion process of sulfate ions from the outside to the concrete. Meanwhile, sulfate ions that have entered but not reacted will further diffuse into the concrete.

\subsection{Model validation}

In this work, COMSOL software was used to solve the coupled model of Section 2 with parameters listed in Table 3. Based on the information of concrete mix proportions and composition of cement presented in Table 1, the initial content of calcium aluminate $\left(c_{C A 0}\right)$, the initial concentrations of hydration products, namely $\mathrm{CH}\left(C_{C H 0}\right)$ and $\mathrm{C}-\mathrm{S}-\mathrm{H}\left(C_{C S H 0}\right)$, the parameters of equivalent reaction coefficient $(q)$, and $\alpha_{s}$, were calculated as using the methods mentioned in [9]. The initial diffusion coefficients of ions in concrete are calculated by Eq. (13), proposed by Garboczi and Bentz [24],

$$
\frac{D_{0}}{D_{w}}=0.001+0.07 \theta^{2}+0.18 \times H(\theta-0.18) \times(\theta-0.18)^{2},
$$

where $D_{w}$ is the diffusion coefficient in free water, $D_{0}$ is the initial diffusion coefficient in the porous materials, $\theta$ is the capillary pores calculated by Power's model [12]. The chemical reaction rate under external sulfate attack is difficult to measure experimentally. Its values vary from $1 \times 10^{-9}$ to $1 \times 10^{-6} \mathrm{~m}^{3} / \mathrm{mol} / \mathrm{s}$ as reported in the literature [25]. In this paper, the reaction rate constants refer to the values in the reference of Zuo et al. [26], as listed in Table 3. The average initial porosity was 0.1206 , standard deviation is 0.001 , obtained with the cube specimens.

In the developed numerical model, the concentration of sulfate ions is calculated and expressed as a mass fraction consistent with the obtained test results. Assuming a micro volume, $\Delta V$, the concentration of sulfate ions is given by:

$$
\zeta=\frac{C_{\mathrm{SO}_{4}^{2}} \times \Delta V \times M_{\mathrm{SO}_{4}^{2-}}}{\rho \times \Delta V}=\frac{C_{\mathrm{SO}_{4}^{2-}} \times M_{\mathrm{SO}_{4}^{2}}}{\rho}
$$

where $C_{\mathrm{SO}}{ }^{2-}$ is the total concentration of sulfate content $\left(\mathrm{mol} / \mathrm{m}^{3}\right)$, including the concentration of sulfate ions in solution, in gypsum, and in ettringite; $M_{\mathrm{so}} 4^{2-\text { is }}$ the molar mass of sulfate ions, equal to $98 \times 10^{-3} \mathrm{~kg} / \mathrm{m}^{3} ; \rho$ is the density of concrete material, taken as $2400 \mathrm{~kg} / \mathrm{m}^{3}$.

Table 3. The main parameters used in the model. 


\begin{tabular}{|c|c|c|}
\hline Parameter & Value & Reference \\
\hline Initial concentration of calcium aluminate $\left(c_{C A 0}\right)$ & $63.57 \mathrm{~mol} / \mathrm{m}^{3}$ & Calculated based on used materials \\
\hline Initial concentration of $\mathrm{CH}\left(\mathrm{C}_{\mathrm{CH} 0}\right)$ & $1135 \mathrm{~mol} / \mathrm{m}^{3}$ & Calculated based on used materials \\
\hline Initial concentration of C-S-H $\left(C_{C S H O}\right)$ & $1049 \mathrm{~mol} / \mathrm{m}^{3}$ & Calculated based on used materials \\
\hline Equivalent reaction coefficient $(q)$ & 3 & Calculated based on used materials \\
\hline$\alpha_{s}$ & $3.03 \times 10^{-4} \mathrm{~m}^{3} / \mathrm{mol}$ & Calculated based on used materials \\
\hline Initial porosity $\left(\varphi_{0}\right)$ & 0.1206 & Calculated based on used materials \\
\hline Initial diffusion coefficient of $\mathrm{Ca}^{2+}$ in concrete $\left(\mathrm{DCa}^{2+}\right)$ & $2.78 \times 10^{-11} \mathrm{~m}^{2} / \mathrm{s}$ & Calculated based on used materials \\
\hline Initial diffusion coefficient of $\mathrm{SO}_{4}{ }^{2-}$ in concrete $\left(\mathrm{SOO}_{4}{ }^{2-}\right)$ & $3.75 \times 10^{-11} \mathrm{~m}^{2} / \mathrm{s}$ & Calculated based on used materials \\
\hline Volume filled fraction $(f)$ & 0.05 & [27] \\
\hline Chemical reaction rate constant in Eq. (1), $\left(k_{1}\right)$ & $1.22 \times 10^{-8} \mathrm{~m}^{3} / \mathrm{mol} / \mathrm{s}$ & {$[26]$} \\
\hline Chemical reaction rate constant in Eq. $(5),\left(k_{2}\right)$ & $1.22 \times 10^{-9} \mathrm{~m}^{3} / \mathrm{mol} / \mathrm{s}$ & [26] \\
\hline
\end{tabular}

Fig. 7 depicts the concentration of sulfate ions obtained by the established model and the experimental results as a function of depth at different immersion times. It can be seen that the concentration of sulfate ions increases to a maximum at a depth of approximately $2 \mathrm{~mm}$ before decreasing with depth. The peak concentration of sulfate ions may be attributed to the precipitation of solid sulfates at a certain depth such as ettringite and gypsum formed by the chemical reactions between the hydrates and penetrating sulfate ions [28,29]. By increasing the immersion time, more sulfate ions penetrate into the concrete, and the penetration depth increases with the diffusion process. Meanwhile, the peak concentration of sulfate ions increases and shifts to greater depths both in the model and experimental results. Further, the trend of the simulation data is in line with the experimental results. It should also be noted that the specific location of the peak concentration of sulfate ions cannot be determined accurately from the experiments. On the one hand, it is not easy to obtain highly dense data points in the experiments; on the other hand, taking the midpoint of each slice fails to consider the result of each exact point in the slice. Overall, the obtained results indicate that the established model is in good agreement with the experimental data. 


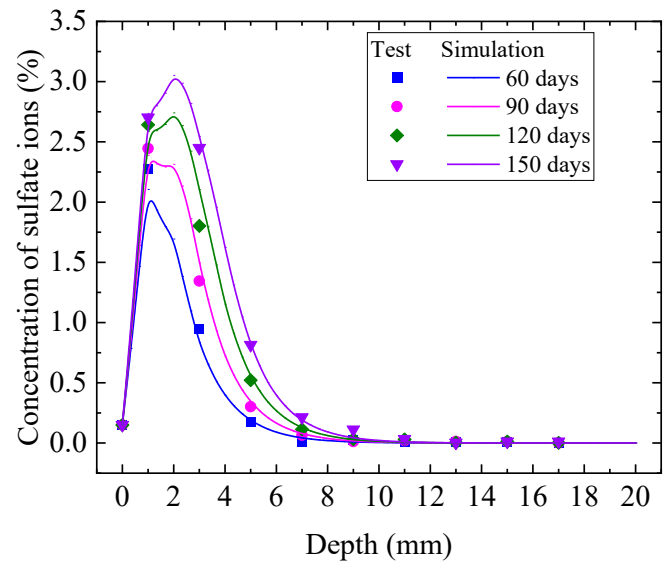

Fig. 7. Concentration of sulfate ions obtained by the established model and the experiments as a function of depth at different immersion times.

\subsection{Parametric study}

To investigate the influences of model parameters, namely the concentration of sulfate solution and temperature, parametric studies were conducted based on the experiments and the presented model. Three different concentrations ( 3 , 5 , and $7 \%)$ at a temperature of $298 \mathrm{~K}$ and three temperatures $(290,298$, and $308 \mathrm{~K})$ at a sulfate solution concentration of $5 \%$ were experimentally studied. Other input parameters for the model are listed in Table 3 . In the case of simulation, the profile of reacted aluminate depletion [30] and the leaching depth [12] are used to evaluate the influence of each parameter. The reacted aluminate depletion is calculated by:

$$
C A^{\text {react }}=c_{C A 0}-c_{C A}
$$

where $c_{C A 0}$ is the initial concentrations of the equivalent calcium aluminates $\left(\mathrm{mol} / \mathrm{m}^{3}\right)$. As shown in Fig. 8, the reaction fronts at three different points (i.e. 95, 50,5\%) of reacted calcium aluminate are defined and the front amplitude is calculated from the difference between the $95 \%$ reaction front and 5\% reaction front. According to the definition by Ikumi et al. [30], the variations of $95 \%$ and $5 \%$ reaction fronts are the best representatives for the influences of parameters on chemical reaction and diffusion process, respectively. The variation of front amplitude indicates which process is more affected by the parameters. Since calcium leaching has a significant effect on sulfate attack [9], the influence of each parameter on the calcium leaching process is also investigated. The leaching depth is defined as the position where portlandite is totally dissolved, and the dissolved content of portlandite $\left(C_{C H}\right)$ is calculated by: 


$$
C_{C H}= \begin{cases}c_{c a}^{s}-C_{C S H 0} & c_{c a}^{s}>C_{C S H 0} \\ C_{C H 0} & c_{c a}^{s} \leq C_{C S H 0}\end{cases}
$$

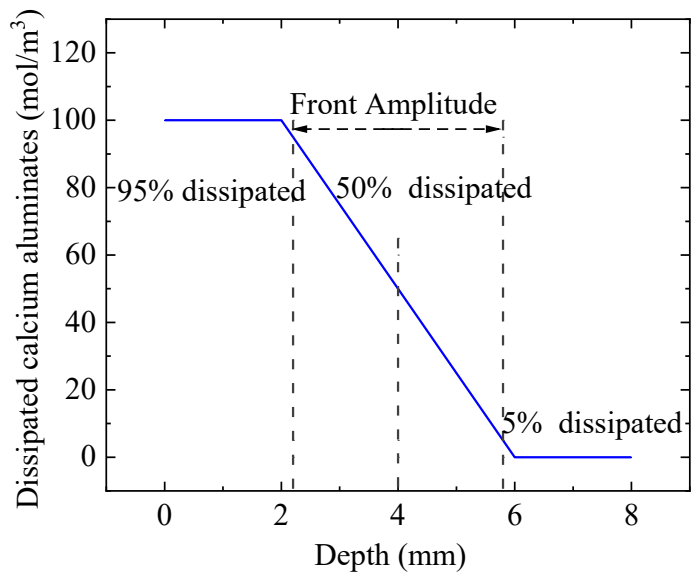

Fig. 8. The aluminate depletion profile.

\subsubsection{Concentration of sulfate solution}

Fig. 9 depicts the experimental and simulation results of the concentration of sulfate ions in concrete at three different concentrations of sulfate solution, namely 3,5 , and $7 \%$, at a temperature of $298 \mathrm{~K}$. The concentration of sulfate ions rises by increasing the concentration of the sulfate solution at given immersion time. Moreover, the penetration depth of sulfate ions increases, and the position of the peak concentration of sulfate ions shifts to greater depths at a higher concentration, which can be attributed to a larger concentration gradient leading to an increase in the diffusion rate [5]. Then, the concentration of sulfate ions that penetrated into the concrete and reacted with hydration products increases. The variation of sulfate content in concrete with immersion time can basically be reflected by the simulation results at different sulfate solution concentrations although there are some differences between the simulation and experimental data at a specific depth. These discrepancies may be due to some errors caused by inaccurate sampling points in the experiments, the details of which are discussed in Section 4.3.2. 


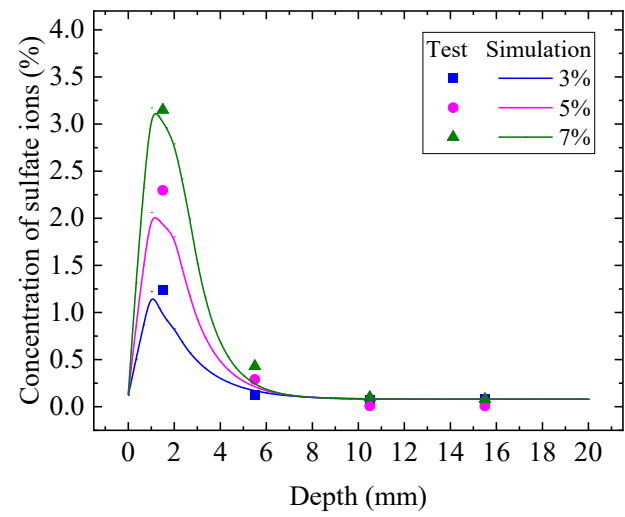

(a) 60 days

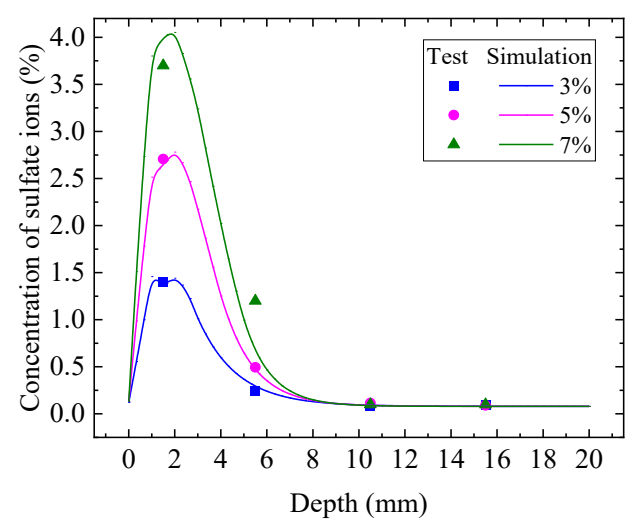

(c) 120 days

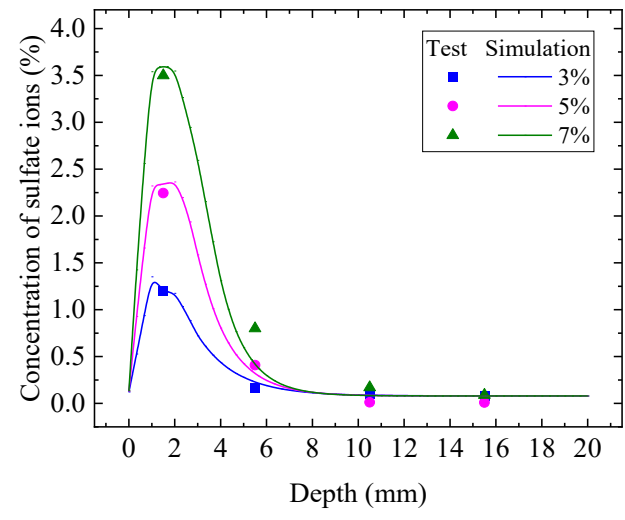

(b) 90 days

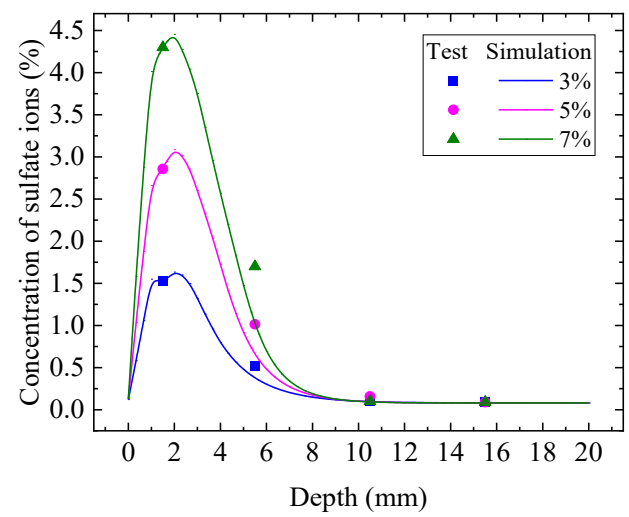

(d) 150 days

Fig. 9. The concentration of sulfate ions at different concentrations of sulfate solution.

The evolution of the selected indicators for reaction fronts and leaching depth is shown in Fig. 10. It is clear that the increments in 95\% reaction front, $5 \%$ reaction front, and the leaching depth gradually decrease with increasing immersion time, i.e. the rates of chemical reactions and diffusion are decreasing at longer immersion times. In Fig. 10(a), the depth of $95 \%$ reaction front increases as the concentration of sulfate solution rises, which means that a concentrated sulfate solution can promote the progress of the chemical reactions. This result is consistent with the data presented in Fig. 10(c), illustrating that the leaching depth rises by increasing the concentration of sulfate solution. Because of the promotion of the chemical reactions, more calcium ions are dissolved, leading to a continuous increase in the leaching depth. The impact of sulfate solution concentration on the chemical reactions is more pronounced in the early stages, i.e. $0-1$ year. At a sulfate solution concentration equal to $7 \%, 95 \%$ of calcium aluminate is firstly consumed in 0.25 years ( 90 days). Moreover, 
compared to a sulfate solution concentration of $3 \%$, the depth of $95 \%$ reaction front increases by $52 \%$ and $79 \%$ at concentrations of 5 and 7\% respectively after one year of immersion. However, the average growths from the second year to the fifth year, are $14 \%$ and $23 \%$ for 5 and $7 \%$ concentration relative to a sulfate solution concentration of $3 \%$, respectively. These outcomes may be explained by the fact that the diffusive sulfate ions are mainly involved in chemical reactions with a higher initial concentration of calcium ions in the early stages rather than continue to diffuse into the concrete. Due to the depletion of the calcium ions with the progress of the chemical reactions, the impact of sulfate solution concentration on the chemical reactions is reduced. Similar results can also be seen in Fig. 10(d), in which as immersion time increases, the front amplitude drops considerably in the early stages and then remains constant in the later stages. Moreover, the front amplitude is smaller in the presence of concentrated sulfate solutions, indicating that the concentration of sulfate solution affects the chemical reactions more noticeably than the diffusion process. This conclusion is supported by Fig. 10(b), in which the concentration of the sulfate solution is shown to make no significant difference in the variation of $5 \%$ reaction front with immersion time. These results suggest that the increased sulfate solution concentration should have a larger effect on the chemical reactions, especially in the early stages.

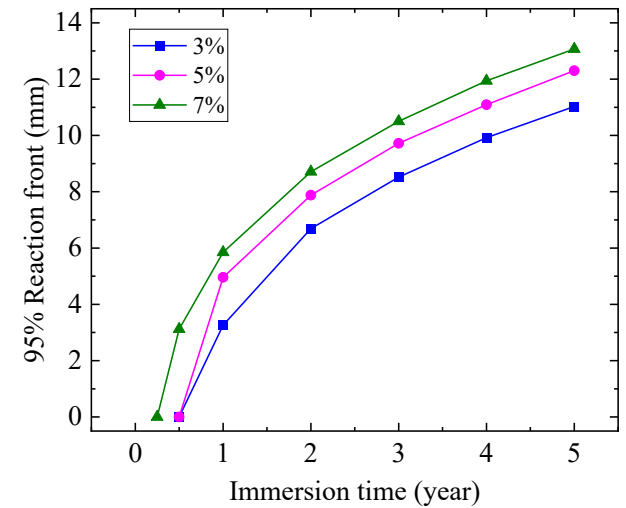

(a) $95 \%$ reaction front

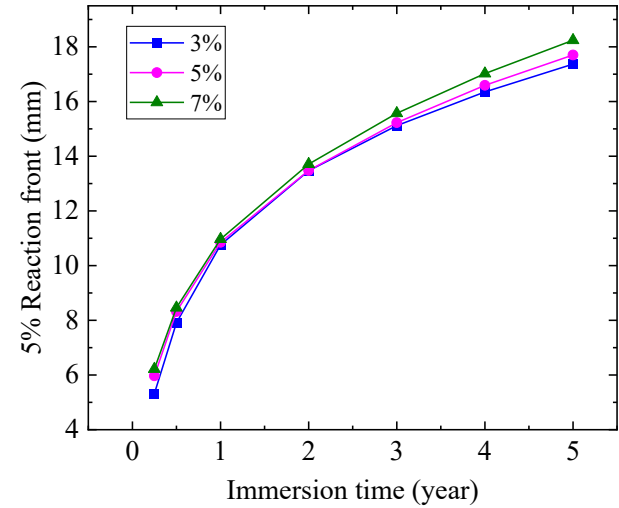

(b) $5 \%$ reaction front 


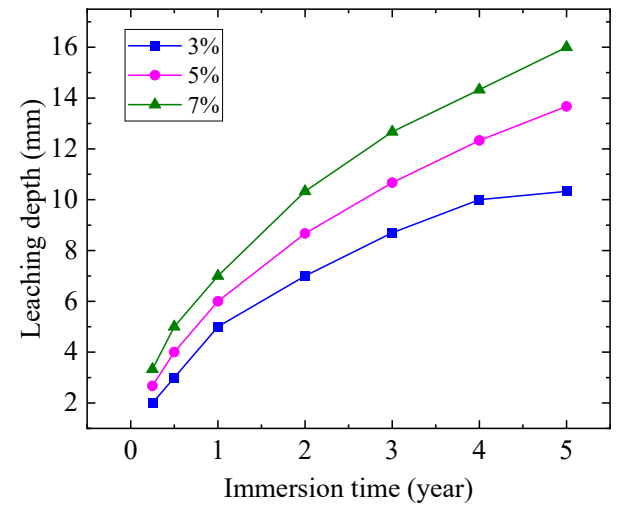

(c) Leaching depth

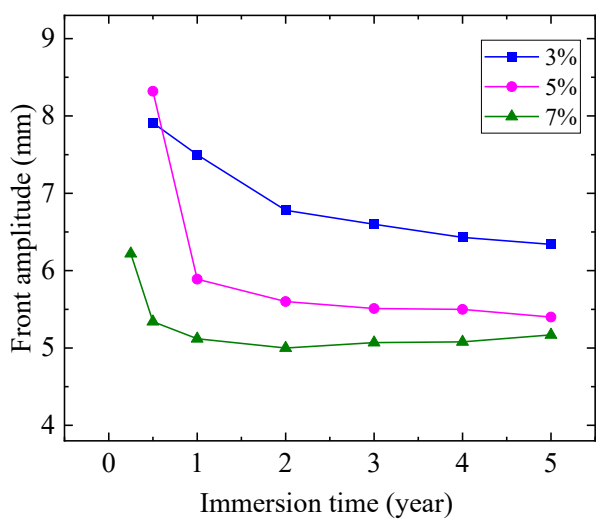

(d) Front amplitude

Fig. 10. The influence of sulfate solution concentration on the defined indicators.

\subsubsection{Temperature}

The results of the concentration of sulfate ions in concrete at three temperatures of 290,298 , and $308 \mathrm{~K}$ and at a concentration of sulfate solution equal to $5 \%$ are illustrated in Fig. 11. It is clearly seen that the concentration of sulfate ions increases by raising temperature, which can be attributed to the increased diffusion coefficient and chemical reaction rate constants at high temperatures [31]. Meanwhile, the penetration depth of sulfate ions rises at a higher temperature, whereas the position of the peak concentration of sulfate ions almost remains unchanged at different temperatures. Although the increased diffusion coefficients promote the diffusion of sulfate ions into the concrete, the increased chemical reaction rates facilitate the consumption of sulfate ions, leaving less sulfate ions to continue diffusing into concrete. This could explain why the peak position does not change with temperature. It should also be noted that there are some differences arising from the inaccurate sampling point in the experiments, between the experimental data and the simulation results, especially for the data points of the second slice.

As mentioned in Section 3, the obtained concentration of sulfate ions for each slice represents the result at the midpoint of the slice. However, the evolution of the concentration of sulfate ions after the peak point has a negative exponential form, indicating that the concentration of sulfate ions drops dramatically with depth. It means that the average value of a certain thickness is represented by the midpoint, which causes the obtained results at the midpoint to be larger than the value at the same depth in the actual condition. Taking the example of the second slice with an immersion time of 120 
days, it can be seen that the experimental results obtained at temperatures of 290, 298, and $308 \mathrm{~K}$ are respectively larger by $14.7,31.8$, and $58.4 \%$ than the corresponding simulation data at a depth of $5.5 \mathrm{~mm}$. It is also worth noting that there is a larger discrepancy between the experimental and simulation results at higher temperatures. In fact, the peak value increases, and the descending part of the curve is steeper at higher temperatures, causing the errors introduced by using the midpoint approximation more significant. By moving the sampling point forward by $0.5 \mathrm{~mm}$ for the second slice, that is, a depth of $5 \mathrm{~mm}$ represents the measured results, the difference is reduced to $7.1 \%$ at an immersion time of 120 days and at a temperature of $298 \mathrm{~K}$. Generally, the established model can basically reflect the effect of temperature on external sulfate attack on concrete.

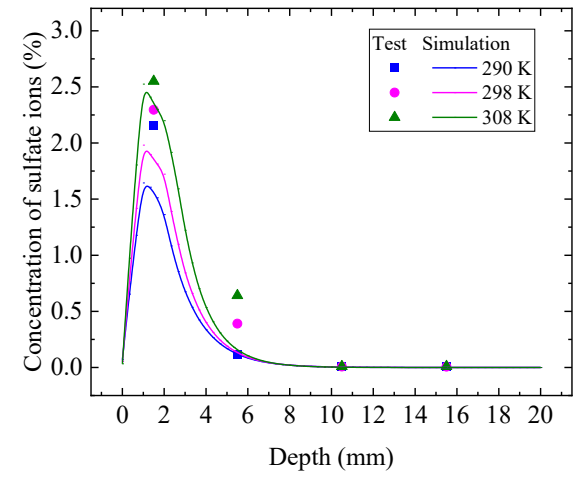

60 days

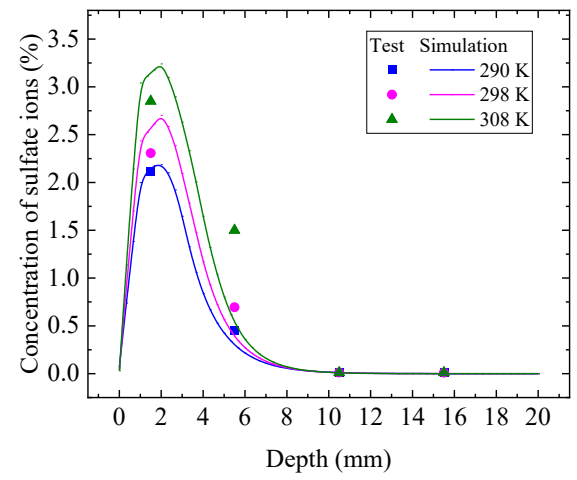

120 days

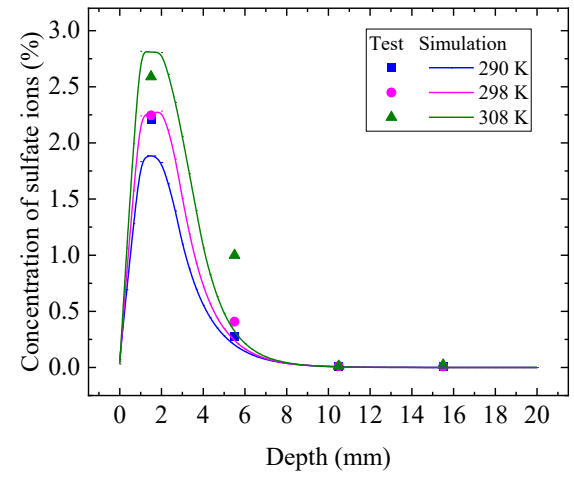

90 days

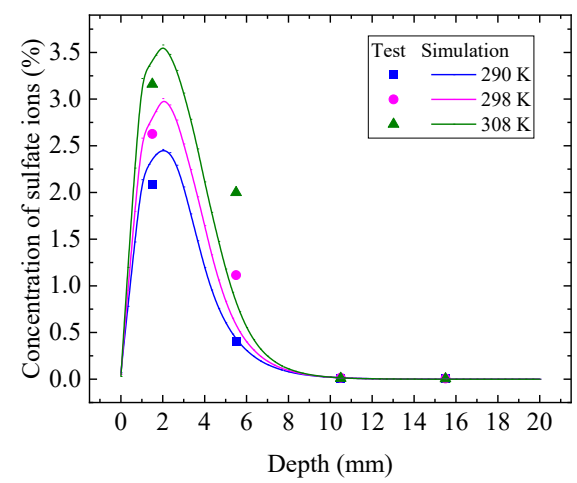

150 days

Fig. 11. The concentration of sulfate ions at different temperatures. 


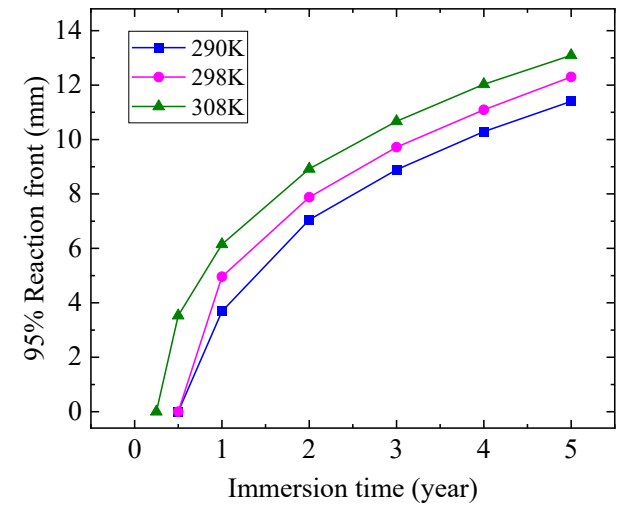

(a) $95 \%$ reaction front

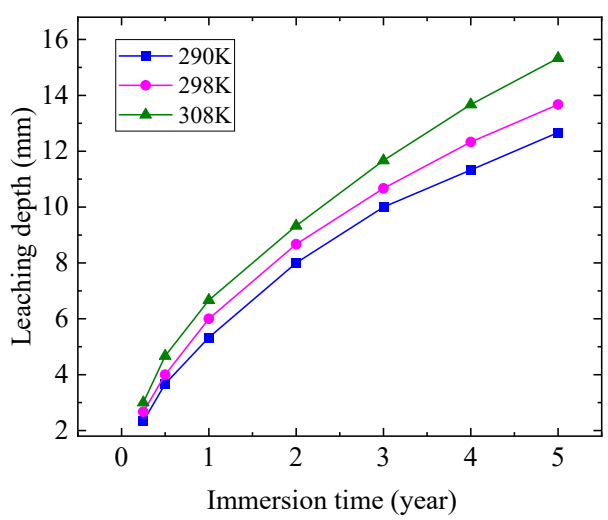

(c) Leaching depth

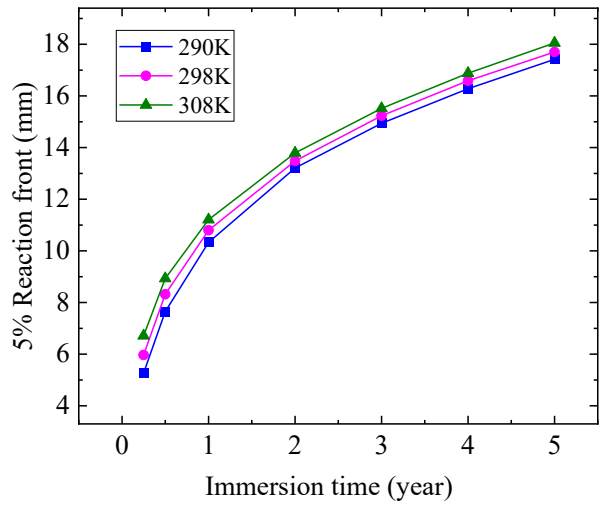

(b) $5 \%$ reaction front

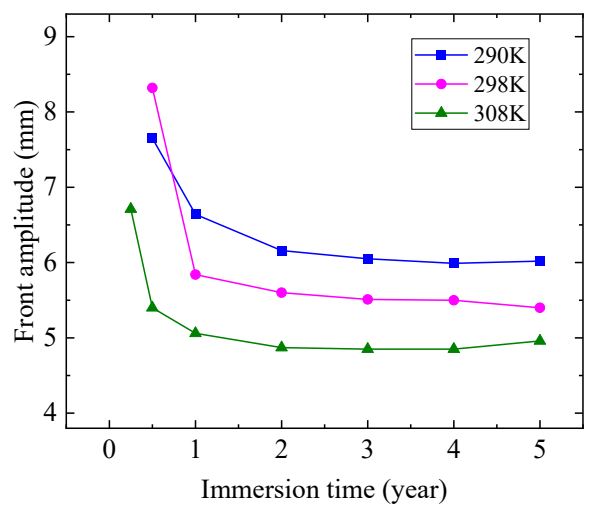

(d) Front amplitude

Fig. 12. The influence of temperature on the defined indicators.

Fig. 12 illustrates the variations of the defined indicators, namely $95 \%$ reaction front, $5 \%$ reaction front, the leaching depth, and front amplitude, with immersion time at three different temperatures. Compared with the influence of the concentration of sulfate solution, a similar trend can be observed, that is, the rate of increments in $95 \%$ reaction front, $5 \%$ reaction front, and the leaching depth gradually decline as the immersion time rises. The leaching depth, 95\% reaction front, and 5\% reaction front are all greater at increased temperatures. These results imply that the chemical reactions and diffusion of ions are both accelerated since raising temperature intensifies the chemical reaction rate constants and diffusion coefficients of ions [32,33]. In addition, as presented in Fig. 12(d), the front amplitude is lower at a higher temperature. A similar conclusion can be drawn that the chemical reaction process is more sensitive to temperature than the diffusion 
process. Moreover, this phenomenon is more noticeable in the early stages, which may be ascribed to the initial content of calcium ions affecting the chemical reaction process inside the concrete.

\section{CONCLUSIONS}

An experimental programme was carried out to validate a recently proposed coupled chemo-transport model for the external sulfate attack on concrete. The experiments and the corresponding numerical simulations for model validation investigated the effects of the concentration of sulfate solution and temperature. Good agreement between results was demonstrated in support of model physical realism. The following main conclusions can be drawn:

- The developed model can predict with acceptable accuracy the distribution of sulfate ions in concrete in the presence of various immersion sulfate solutions and at different temperatures.

- The external sulfate attack on concrete is accelerated in the presence of concentrated sulfate solutions and at a higher temperature as an increased concentration of sulfate ions is observed.

- Specifically, the chemical reactions between the diffusive sulfate ions and hydration products are enhanced strongly by increasing the concentration of sulfate solution and temperature. The effects of sulfate solution concentration and temperature are stronger in the early stages of immersion ( $0-1$ year), which is related to the concentration of calcium ions in the concrete reacting with penetrating sulfate ions. As a consequence of the enhanced chemical reactions, calcium leaching is facilitated, which is reflected by a greater leaching depth.

- The front amplitude is lower at concentrated sulfate solutions and higher temperatures, which means the concentration of sulfate solution and temperature influence the external sulfate attack on concrete predominantly via the chemical reaction process.

\section{FUNDING}

This research received grants from the National Natural Science Foundation of China (Grant Nos. 51678200, 51678205, 51978211, 51878225), and the Program of Shenzhen Science and Technology Plan (Grant No. JCYJ20170811160514862). 


\section{REFERENCES}

[1] R. Ragoug, O.O. Metalssi, F. Barberon, J.M. Torrentid, N. Roussele, L. Divetf, J.B. Lacaillerie, Durability of cement pastes exposed to external sulfate attack and leaching: Physical and chemical aspects, Cem. Concr. Res. 116 (2019) $134-145$.

[2] G.J. Yin, X.B. Zuo, X.H. Sun, Y.J. Tang, Macro-microscopically numerical analysis on expansion response of hardened cement paste under external sulfate attack, Constr. Build. Mater. 207 (2019) 600-615.

[3] N. Cefis, C. Comi, Chemo-mechanical modelling of the external sulfate attack in concrete, Cem. Concr. Res. 93 (2017) 57-70.

[4] T. Ikumi, I. Segura, Numerical assessment of external sulfate attack in concrete structures. A review, Cem. Concr. Res. 121 (2019) 91-105.

[5] C. Sun, J. Chen, J. Zhu, M. Zhang, J. Ye, A new diffusion model of sulfate ions in concrete, Constr. Build. Mater. 39 (2013) 39-45.

[6] Y. Yu, Y.X. Zhang, Numerical modelling of mechanical deterioration of cement mortar under external sulfate attack, Constr. Build. Mater. 158 (2018) 490-502.

[7] T. Liu, D. Zou, J. Teng, G. Yan, The influence of sulfate attack on the dynamic properties of concrete column Constr. Build. Mater. 28(1) (2012) 201-207.

[8] T. Liu, S. Qin, D. Zou, W. Song, Experimental investigation on the durability performances of concrete using cathode ray tube glass as fine aggregate under chloride ion penetration or sulfate attack, Constr. Build. Mater. 163 (2018) 634-642.

[9] S.S. Qin, D.J Zou, T.J. Liu, A.P. Jivkov, A chemo-transport-damage model for concrete under external sulfate attack, Cem. Concr. Res. 132 (2020) 106048.

[10] M. Jebli, F. Jamin, E. Garcia-Diaz, M. El Omari, M.S. El Youssoufi, Influence of leaching on the local mechanical properties of an aggregate-cement paste composite, Cem. Concr. Compos. 73 (2016) 241-250.

[11] K. Kurumisawa, K. Haga, D. Hayashi, H. Owada, Effects of calcium leaching on diffusion properties of hardened and altered cement pastes, Phys. Chem. Earth Pt. A/B/C 99 (2017) 175-183.

[12] Q.T. Phung, N. Maes, D. Jacques, J. Perko, G. De Schutter, G. Ye, Modelling the evolution of microstructure and transport properties of cement pastes under conditions of accelerated leaching, Constr. Build. Mater. 115 (2016) 179- 
192.

[13] Y.S. Choi, E.I. Yang, Effect of calcium leaching on the pore structure, strength, and chloride penetration resistance in concrete specimens, Nucl. Eng. Des. 259 (2013) 126-136.

[14] R. Tixier, B. Mobasher, Modeling of damage in cement-based materials subjected to external sulfate attack. I: formulation, J. Mater. Civ. Eng. 15(4) (2003) 305-313.

[15] A.E. Idiart, C.M. López, I. Carol, Chemo-mechanical analysis of concrete cracking and degradation due to external sulfate attack: a meso-scale model, Cem. Concr. Compos. 33(3) (2011) 411-423.

[16] E. Samson, G. Lemaire, J. Marchand, J.J. Beaudoin, Modeling chemical activity effects in strong ionic solutions, Comput. Mater. Sci. 15(3) (1999) 285-294.

[17] J. Jain, N. Neithalath, Analysis of calcium leaching behavior of plain and modified cement pastes in pure water, Cem. Concr. Compos. 31(3) (2009) 176-185.

[18] K. Wan, Y. Li, W. Sun, Experimental and modelling research of the accelerated calcium leaching of cement paste in ammonium nitrate solution, Constr. Build. Mater. 40 (2013) 832-846.

[19] K. Nakarai, T. Ishida, K. Maekawa, Modeling of calcium leaching from cement hydrates coupled with micro-pore formation, J. Adv. Concr. Technol. 4(3) (2006) 395-407.

[20] K. Wan, L. Li, W. Sun, Solid-liquid equilibrium curve of calcium in $6 \mathrm{~mol} / \mathrm{L}$ ammonium nitrate solution, Cem. Concr. Res. 53 (2013) 44-50.

[21] GB, T, 50081, Standard for Test Method of Mechanical Properties on Ordinary Concrete, China Architecture and Building press, Beijing, 2002.

[22] GB, T, 13025.8, General Test Method in Salt Industry-Determination of Sulfate, Chinese GB standards, Beijing, 2012.

[23] D. Sun, K. Wu, H. Shi, L. Zhang, L. Zhang, Effect of interfacial transition zone on the transport of sulfate ions in concrete, Constr. Build. Mater. 192 (2018) 28-37.

[24] E.J. Garboczi, D.P. Bentz, Computer simulation of the diffusivity of cement-based materials, J. Mater. Sci. 27(8) (1992) 2083-2092.

[25] R. Tixier, Microstructural development and sulfate attack modeling in blended cement-based materials, Doctoral dissertation, Arizona State University, 2000. 
[26] X.B. Zuo, W. Sun, C. Yu, Numerical investigation on expansive volume strain in concrete subjected to sulfate attack, Constr. Build. Mater. 36 (2012) 404-410.

[27] T. Ikumi, S.H. Cavalaro, I. Segura, A.D. La Fuente, A. Aguado, Simplified methodology to evaluate the external sulfate attack in concrete structures, Mater. Des. 89 (2016) 1147-1160.

[28] S. Sarkar, S. Mahadevan, J.C.L. Meeussen, H. van der Sloot, D.S. Kosson, Numerical simulation of cementitious materials degradation under external sulfate attack, Cem. Concr. Compos. 32(3) (2010) 241-252.

[29] Y. Yu, Y.X. Zhang, A. Khennane, Numerical modelling of degradation of cement-based materials under leaching and external sulfate attack, Comput. Struct. 158 (2015) 1-14.

[30] T. Ikumi, S.H. Cavalaro, I. Segura, A. Aguado, Alternative methodology to consider damage and expansions in external sulfate attack modeling, Cem. Concr. Res. 63 (2014) 105-116.

[31] K. Yokozeki, K. Watanabe, D. Hayashi, N. Sakata, N. Otsuki, Modeling of ion diffusion coefficients in concrete considering with hydration and temperature effects, Doboku Gakkai Ronbunshu, 2003(725) (2003)131-142.

[32] K. Yokozeki, K. Watanabe, N. Sakata, N. Otsuki, Modeling of leaching from cementitious materials used in underground environment, Appl. Clay Sci. 26(1-4) (2004) 293-308.

[33] M. Santhanam, M.D. Cohen, J. Olek, Modeling the effects of solution temperature and concentration during sulfate attack on cement mortars, Cem. Concr. Res. 32(4) (2002) 585-592. 